\title{
Inhibition Performances of Nicotinamide Against Aluminum Corrosion in an Acidic Medium
}

\author{
S. Bashir, ${ }^{a}$ V. Sharma, ${ }^{a}$ S. Kumar, ${ }^{a}$ \\ Z. Ghelichkhah, ${ }^{b, c}$ Ime B. Obot ${ }^{d}$ and A. Kumar ${ }^{a, *}$ \\ ${ }^{a}$ Department of Chemistry, Faculty of Technology and Sciences, \\ Lovely Professional University, Phagwara, Punjab, India \\ ${ }^{b}$ Department of Chemistry, Faculty of Science, Urmia University, Urmia, Iran \\ ${ }^{c}$ Department of Engineering Physics, University of Wisconsin Madison, USA \\ ${ }^{d}$ Center of Research Excellence in Corrosion, King Fahd University of Petroleum \\ and Minerals, Dhahran 31261, Saudi Arabia
}

Received February 27, 2018; accepted June 10, 2018

\begin{abstract}
The non-toxic anticorrosion properties of nicotinamide have been studied on aluminum in an acidic medium. The techniques included weight loss method, electrochemical measurements, quantum chemical calculations, Monte Carlo simulation, infra-red spectroscopy and scanning electron microscopy. This study gathers information about the inhibitor molecule adsorption onto the surface of metal specimens. Thermodynamic parameters were utilized to predict the adsorption mechanism. The dependence of corrosion inhibition efficiency on various parameters was examined, and it was seen that the increase in the inhibitor concentration and in temperature led to an increase in the inhibition efficiency. The dipole moment and $\mathrm{E}_{\text {HOMO-}} \mathrm{E}_{\mathrm{LUMO}}$ influenced the inhibition efficiency, which was observed by quantum chemical studies.
\end{abstract}

Keywords: corrosion inhibition, electrochemical studies, molecular dynamic simulations, nicotinamide, quantum chemical parameters.

\section{Introduction}

Aluminum corrosion is the subject of critical technological importance, due to this metal's increasing industrial applications [1-2]. Aluminum and its alloys represent an important category of materials, due to their wide applicability, especially in aerospace, household, industries, automotive, transportation and marine technology, mainly because of their good specific strength and excellent formability.

Corrosion inhibitors are the chemical compounds which, when added in small concentrations to the environment, minimize or prevent corrosion [3].

\footnotetext{
* Corresponding author. E-mail address: drashishchemlpu@gmail.com
} 
Considering the alternatives to toxic corrosion inhibitors, some studies used drugs as corrosion inhibitors of metals and their alloys [4-5]. Owing to their structural similarities with the commercially used corrosion inhibitors, and to their non-toxic behaviour, they have proved to be a great breakthrough in the formation of environmentally safe corrosion inhibitors [6-7].

Literature shows that Ethambutol [8], Ethanolamine and Ethylamine [9], Streptoquin and Septazole [10], Sulfamethoxazole [11], Streptomycin [12], Pheniramine [13], Thiadiazoles [14], Fluconazole [15], Miconazole Nitrate [16], Dicioxacillin [17], Atorvastatin [18], Ciprofloxacin [19], Tinidazole [20], Rhodanine Azosulpha [21], Mebendazole [22], Paracetamol and Carbamazepin [23], Anthranillic acid [24], Amoxicillin [25], Ampicillin [26], Cloxacilin [27] and Cefixime [28] are good corrosion inhibitors. In our search for non-toxic corrosion inhibitors, this work focused on using nicotinamide as an aluminum corrosion inhibitor in an acidic medium. Nicotinamide can serve as a potentially good aluminum corrosion inhibitor, due to the presence of $\mathrm{N}$ and $\mathrm{O}$ in its structure. The molecular structure of nicotinamide is given in Fig. 1.

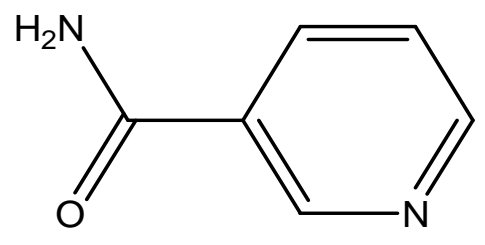

Figure 1. Schematic representation of nicotinamide's structure.

\section{Experimental}

\section{Weight loss method}

Aluminum $(0.35 \% \mathrm{Fe}, 0.25 \% \mathrm{Si}, 0.05 \% \mathrm{Cu}, 0.05 \% \mathrm{Zn}, 0.03 \% \mathrm{Mg}, 0.03 \% \mathrm{Mn}$, $0.03 \% \mathrm{Ti}$ and the remainder $(99.60 \% \mathrm{Al})$ was used. The aggressive solutions $(0.2$ M, 0.4 M, 0.5 M, 0.6 M, 0.8 M, 1 M, 1.25 M and 1.50 M HCl) were prepared by dilution of analytical reagent grade $98 \% \mathrm{HCl}$ with distilled water. The initial inhibitory solution was prepared from the dissolution of (>98\% purity) nicotinamide from LobaChem in $\mathrm{HCl}$ and $\mathrm{H}_{2} \mathrm{O}$.

Weight loss was measured on aluminum sheets with a surface area of $10 \mathrm{~cm}^{2}$. These sheets were progressively rubbed with fine emery paper from 600 to 1200 grades, washed with water, followed by degreasing with acetone, then dried and weighed before immersion in $100 \mathrm{~mL}$ corrosive medium.

\section{Electrochemical measurements}

The working cathode (WE) for the potentiodynamic studies was formed from an aluminum rod, and was bound towards one side with a protected copper wire, which was then inserted in synthetic epoxy sap (ARALDITE), leaving the uncovered surface region of $1 \mathrm{~cm}^{2}$ for the studies. The counter anode was platinum, and the reference electrode was a soaked calomel terminal (SCE) [29]. The capability of the metal terminal versus the reference cathode was measured 
with the help of a galvanostat. The utilized terminal framework was for potentiostatic polarization and electrochemical impedance spectroscopy. Potentiodynamic polarization and potentiostatic polarization estimations were performed using a CHI 760 electrochemical analyser instrument which was under circulated air.

\section{Quantum chemical calculations and Monte Carlo simulation}

Quantum chemical analysis was performed using the MNDO and AM1 method of the MOPAC 6.0 quantum chemical package of Hyperchem 7.5. The algorithm used for computation was Polak-Rieberre, which is fast and accurate. Geometry optimization was performed on nicotinamide by DFT, employing the functional BLYP together with the generalized gradient approximation (GGA), using the DNP basis sets. A vibrational analysis was carried out for each optimized molecule, to ensure that they were at a minimum level on the potential energy surface (no imaginary frequency). The convergence criteria and the global orbital cut-offs were fine-tuned before the calculations. The tolerances of energy, gradient and displacement convergence were $1 \times 10^{-5} \mathrm{Ha}, 2 \times 10^{-5} \mathrm{Ha}^{-1}$ and $5 \times$ $10^{-3} \AA$, respectively. Direct inversion in an iterative subspace (DIIS) and an orbital occupancy smearing parameter of $0.005 \mathrm{Ha}$ were used to speed up SCF convergence. The effect of the aqueous solvent was simulated by re-optimizing all the geometries at the BLYP/DNP level, using COSMO (conductor-like screening model). Monte Carlo simulations using the Adsorption Locator and Forcite codes implemented in the 6.0 Material Studio software, from Accelrys Inc. (USA), were adopted to compute the adsorption energy of the interaction between nicotinamide and Al surfaces. For the whole simulation procedure, the Compass force field was used to optimize the structures of all components of the system of interest. The simulations were carried out in the simulation boxes (42 $\AA \times 42 \AA \times 55 \AA$ ) with $\alpha=90.00^{\circ}, \beta=90.00^{\circ}$ and $\gamma=90.00^{\circ}$, with periodic boundary conditions, in order to simulate a representative part of an interface devoid of any arbitrary boundary effects. The Al (111) planes were next enlarged to a $10 \times 10$ supercell. A vacuum slab of $50 \AA$ thickness was built above the surfaces, to convert the system to $3 \mathrm{D}$ periodicity. The optimized inhibitor using the Forcite code was then added near the Al (111) surface, and a Monte Carlo simulation annealing procedure was carried out.

\section{FTIR spectral analysis}

The FTIR studies were performed by setting overnight the aluminum coupon in an aqueous solution of nicotinamide, trailed by drying in a microwave. Examination was made between pure nicotinamide and nicotinamide containing aluminum. Shimadzu-1800 FTIR was utilized for this investigation.

\section{Surface morphological studies}

Aluminum samples with the dimensions of $1 \mathrm{~cm} \times 1 \mathrm{~cm} \times 1 \mathrm{~cm}$ were utilized for SEM. The samples were submerged in $0.5 \mathrm{M} \mathrm{HCl}$, with $4000 \mathrm{ppm}$ of the inhibitor in $0.5 \mathrm{M} \mathrm{HCl}$ for $24 \mathrm{~h}$, at room temperature. The specimens were removed from the solutions and dried in desiccators for $24 \mathrm{~h}$, and utilized for SEM. SEM estimations were performed using a 6510LV GEOL JAPAN. 


\section{Result and discussion}

\section{Weight loss measurements}

Aluminum coupons were exposed to $0.5 \mathrm{M} \mathrm{HCl}$ without and with the inhibitor. Weight loss of the coupon was carried out to calculate the corrosion inhibition efficiency, by using the following equation [29]:

$$
\eta \%=W_{0}-\frac{w_{i}}{W_{0}} \times 100
$$

where $\mathrm{W}_{0}$ and $\mathrm{W}_{\mathrm{i}}$ are the initial and the final weight of the aluminum coupon, respectively, and $\eta \%$ is the inhibition efficiency.

The results are shown in Table 1. It can be observed that, as the inhibitor concentration increases, the inhibition efficiency also increases, suggesting the formation of a protective layer by a wider surface coverage [29-30].

Table 1. Weight loss parameters for aluminum in $0.5 \mathrm{M} \mathrm{HCl}$, without and with various concentrations of nicotinamide.

\begin{tabular}{ccccc}
\hline $\begin{array}{c}\text { Conc. } \\
\text { (ppm) }\end{array}$ & $\mathbf{W}_{\mathbf{0}}$ & $\mathbf{W}_{\mathbf{i}}$ & $\mathbf{W}_{\mathbf{0}}-\mathbf{W}_{\mathbf{i}}$ & $\boldsymbol{\eta} \boldsymbol{\%}$ \\
\hline $0.5 \mathrm{M} \mathrm{HCl} \mathrm{(blank)}$ & 0.32 & 0.25 & 0.070 & \\
1000 & 0.34 & 0.34 & 0.008 & 89.5 \\
2000 & 0.29 & 0.29 & 0.006 & 92.1 \\
3000 & 0.32 & 0.32 & 0.004 & 93.8 \\
4000 & 0.30 & 0.30 & 0.002 & 96.1 \\
\hline
\end{tabular}

The inhibition efficiency of the inhibitor with respect to temperature has been studied. It was observed, as the temperature was increased, that the inhibition efficiency decreased [31-34]. The data are given in Table 2.

\section{Thermodynamic studies}

The data obtained from thermodynamic parameters play a very important role in deciding the mechanism involved in the corrosion inhibition process. Various parameters have been evaluated, such as Gibb's free energy, heat of enthalpy, heat of adsorption and entropy.

Table 2.Variation of the inhibition efficiency towards temperature, by weight loss method.

\begin{tabular}{cccclc}
\hline Temperature $(\mathbf{K})$ & & $\mathbf{W}_{\mathbf{0}}$ & $\mathbf{W}_{\mathbf{i}}$ & $\mathbf{W}_{\mathbf{0}}-\mathbf{W}_{\mathbf{i}}$ & $\boldsymbol{\eta} \boldsymbol{\%}$ \\
\hline \multirow{2}{2}{298} & blank & 0.30 & 0.21 & 0.09 & 97.31 \\
& inhibitor & 0.34 & 0.34 & 0.003 & \\
303 & Blank & 0.32 & 0.24 & 0.07 & 96.194 \\
& inhibitor & 0.32 & 0.32 & 0.002 & \\
308 & blank & 0.29 & 0.19 & 0.09 & 84.32 \\
& inhibitor & 0.29 & 0.28 & 0.014 & \\
& blank & 0.27 & 0.18 & 0.10 & 82.644 \\
& inhibitor & 0.27 & 0.25 & 0.017 & \\
\hline
\end{tabular}

The equation used in calculating the free energy of adsorption was:

$$
\Delta G_{\text {ads }}^{0}=-2.303 R T \log (55.5 \mathrm{Kads})
$$


where $\mathrm{T}$ is the absolute temperature, and the constant value of 55.5 is the molar water concentration. $\Delta \mathrm{G}^{\circ}$ ads negative values suggest the spontaneity of the adsorption process and the stability of the adsorbed film onto the aluminum surface. It is usually accepted that $\Delta \mathrm{G}^{\circ}$ ads values around $-20 \mathrm{~kJ} \mathrm{~mol}^{-1}$ or lower indicate electrostatic interaction between charged metal surfaces and charged organic molecules in the bulk of the solution (physisorption process), while those around $-40 \mathrm{~kJ} \mathrm{~mol}^{-1}$ or higher involve charge sharing or charge transfer between the metal surface and organic molecules (chemisorption process) [35]. The calculated $\Delta \mathrm{G}_{\mathrm{ads}}$ and $\mathrm{K}_{\mathrm{ads}}$ values are presented in Table 3 .

Table 3. Activation parameters for aluminum in a $0.5 \mathrm{M} \mathrm{HCl}$ solution, without and with different concentrations of nicotinamide.

\begin{tabular}{ccccc}
\hline $\begin{array}{c}\text { Concentration } \\
(\mathrm{ppm})\end{array}$ & $\begin{array}{c}E_{\mathrm{a}} \\
\left(\mathrm{KJ} \mathrm{mol}^{-1}\right)\end{array}$ & $\begin{array}{c}\Delta H^{\circ} \text { ads } \\
\left(\mathrm{kJ} \mathrm{mol}^{-1}\right)\end{array}$ & $\begin{array}{c}\Delta \mathrm{S}^{\circ} \text { ads } \\
\left(\mathrm{J} \mathrm{mol}^{-1} \mathrm{~K}^{-1}\right)\end{array}$ & $\begin{array}{c}\Delta \mathrm{G}^{\circ} \text { ads } \\
\left(\mathrm{kJmol}^{-1}\right)\end{array}$ \\
\hline & & & & \\
Blank $(0.5 \mathrm{M} \mathrm{HCl})$ & 95.7 & 54.6 & 22.0 & - \\
$4000 \mathrm{ppm}$ & 138.3 & 61.2 & 24.1 & -19.6 \\
\hline
\end{tabular}

It is worth noting that $-\Delta \mathrm{H}^{\circ}$ ads $/ \mathrm{R}$ is the slope of the straight line $\left(\ln \mathrm{K}_{\mathrm{ads}}\right) \mathrm{vs} .1 / \mathrm{T}$, according to the Van't Hoff equation:

$$
\ln \operatorname{Kads}=-\left(\frac{\Delta H_{a d s}^{0}}{R T}\right)+C
$$

where $\mathrm{R}$ is the gas constant $\left(\mathrm{R} \approx 8.314 \mathrm{~J} \mathrm{~K}^{-1} \mathrm{~mol}^{-1}\right)$ and $\mathrm{T}$ is the absolute temperature, respectively. The adsorption heat $\left(\Delta \mathrm{H}_{\mathrm{ads}}\right)$ can be regarded as the standard adsorption heat $\left(\Delta \mathrm{H}^{\circ}{ }_{\text {ads }}\right)$, because such experimental was carried out at the standard pressure and low solution concentration. The numerical value of $\Delta \mathrm{H}^{\circ}$ ads was calculated in Table 3 . The negative sign of the standard adsorption heat indicated that the adsorption process of the inhibitor is an exothermic process, which explains that the corrosion inhibition efficiency decreased with increasing temperatures.

Thus, the standard adsorption entropy $\left(\Delta S^{\circ}\right.$ ads $)$ could be obtained by the following thermodynamic basic equation:

$$
\Delta \mathrm{G}_{\mathrm{ads}}^{0}=\Delta \mathrm{H}_{\mathrm{ads}}^{0}-\mathrm{T} \Delta \mathrm{S}_{\mathrm{ads}}^{0}
$$

$\Delta \mathrm{S}^{\circ}$ ads positive values (in Table 4) suggest that the inhibitor adsorption is coupled with an increase of the system disorder.

Arrhenius equation and the alternative formulations were used to elucidate the corrosion inhibition mechanism [36-37].

$$
\begin{gathered}
C R=K \exp \left(-\frac{E a}{R T}\right) \\
C R=\frac{R T}{N h} \exp \left(\frac{\Delta S}{R}\right) \exp \left(-\frac{\Delta H}{R T}\right)
\end{gathered}
$$


where $E_{a}$ is the activation energy of the corrosion process, $K$ is the preexponential factor, $\mathrm{R}$ is the general gas constant, $\mathrm{h}$ is the Plank's constant, $\mathrm{N}$ is Avogadro's number, $\Delta S$ is the apparent entropy of activation and $\Delta H$ is the apparent enthalpy of activation.

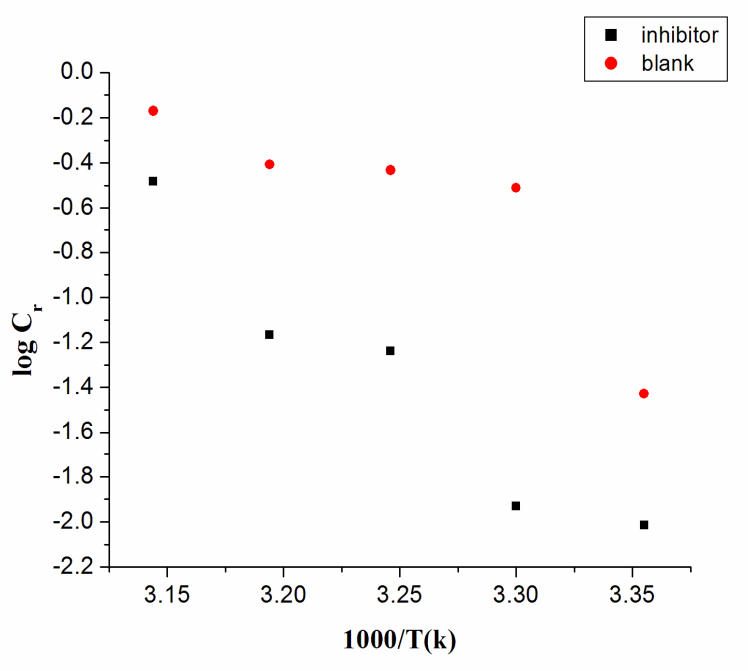

Figure 2. Arrhenius plot for the $0.5 \mathrm{M} \mathrm{HCl}$ solutions with and without nicotinamide.

A plot of log of the corrosion rate obtained by weight loss measurement vs. 1/T gave a straight line, as shown in Fig. 2, with a slope of $-E_{a} / 2.303 R$. The activation energy values are listed in Table $3 . \mathrm{E}_{\mathrm{a}}$ values that are higher in the inhibitor presence than in its absence can be interpreted as an indication of the adsorption effects. In the inhibitor presence, $E_{a}$ increased values, in general, reflected its good ability to hinder aluminum corrosion under such conditions. In other words, the inhibitor adsorption onto the electrode surface led to the formation of a physical barrier that reduced the metal reactivity in the corrosion electrochemical reactions.

\section{Adsorption isotherm}

The type of adsorption isotherm can provide additional information about the properties of the tested compounds, and the adsorption depends on the compounds' chemical composition, temperature and electrochemical potential at the metal/solution interface. In fact, the water molecules could also adsorb onto the metal/solution interface. Thus, the so-called adsorption can be regarded as a quasi-substitution process between the inhibitor in the aqueous phase [ $\operatorname{Inh}_{(\mathrm{sol})}$ ] and water molecules at the electrode surface $\left[\mathrm{H}_{2} \mathrm{O}(\right.$ ads $\left.)\right]$ :

$$
\mathrm{Inh}_{(\mathrm{sol})}+\mathrm{n} \mathrm{H}_{2} \mathrm{O}_{(\mathrm{ads})} \longrightarrow \mathrm{Inh}_{(\mathrm{ads})}+\mathrm{n} \mathrm{H}_{2} \mathrm{O}_{(\mathrm{sol})}
$$

where $\operatorname{Inh}_{(\text {sol })}$ and $\operatorname{Inh}_{(\mathrm{ads})}$ are the inhibitor solutions dissolved in the aqueous solution and adsorbed onto the metallic surface, respectively.

According to Langmuir adsorption isotherm, $\theta$ is related to the equilibrium adsorption constant $\left(\mathrm{K}_{\mathrm{ads}}\right)$ and $\mathrm{C}_{\mathrm{inh}}$ by the following equation: 


$$
C_{i n h} / \boldsymbol{\theta}=1 / K_{a d s}+C_{i n h}
$$

Fig. 3 shows the straight lines of $\mathrm{C}_{\mathrm{inh}} / \theta$ vs. $\mathrm{C}_{\mathrm{inh}}$ at different temperatures. These results show that all the linear correlation coefficients are almost equal to 1 , and that the slopes are close to 1 , which confirm that nicotinamide adsorption onto the aluminum surface obeyed the Langmuir adsorption isotherm.

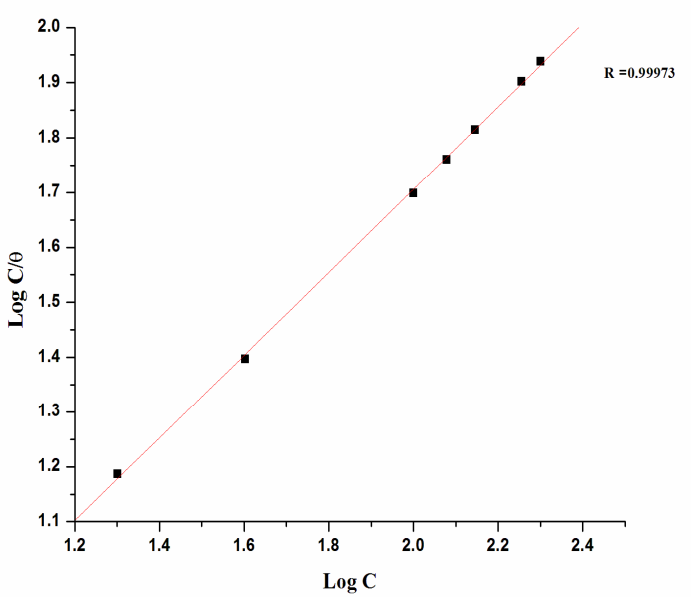

Figure 3. Langmuir adsorption isotherm plot for aluminum corrosion in the inhibitor presence.

\section{FTIR spectroscopy}

FTIR spectra of pure nicotinamide and the resulting solution of nicotinamide after $24 \mathrm{~h}$ of aluminum immersion are shown in Fig. 4. FTIR spectra show differences in the IR spectra, which were observed due to the difference in the interaction of aluminum with nicotinamide. The change in IR bands from 3436 to 2962 shows the interaction of $\mathrm{N}$ and $\mathrm{O}$ with $\mathrm{Al}$, hence leading to the formation of the $\mathrm{Al} /$ nicotinamide complex.

Table 4. Aluminum corrosion parameters in $0.5 \mathrm{M} \mathrm{HCl}$, in nicotinamide presence, at $298 \mathrm{~K}$.

\begin{tabular}{ccccccc}
\hline $\begin{array}{c}\text { Temp } \\
(\mathbf{K})\end{array}$ & Conc. $(\mathbf{p p m})$ & $\begin{array}{c}(-) \mathbf{E}_{\text {corr }} \\
(\mathbf{m V})\end{array}$ & $\begin{array}{c}\mathbf{b}_{\boldsymbol{a}} \\
(\mathbf{m V} / \mathbf{d e c})\end{array}$ & $\begin{array}{c}\mathbf{b}_{\boldsymbol{c}} \\
(\mathbf{m V} / \mathbf{d e c})\end{array}$ & $\begin{array}{c}\mathbf{I}_{\text {corr }} \\
\left(\mathbf{m A} / \mathbf{c m}^{\mathbf{2}}\right)\end{array}$ & $\begin{array}{c}\boldsymbol{\eta} \\
\boldsymbol{\%}^{\%}\end{array}$ \\
\hline 298 & 1000 & 711 & 296.38 & 327.54 & 1.94 & 93.31 \\
298 & 2000 & 715 & 308.45 & 336.24 & 1.23 & 95.73 \\
298 & 3000 & 703 & 258.59 & 349.16 & 0.68 & 97.65 \\
298 & 4000 & 743 & 268.88 & 257.86 & 0.002 & 99.99 \\
298 & $0.5 \mathrm{M} \mathrm{HCl}$ & 700 & 221.48 & 222.32 & 29.02 & \\
\hline
\end{tabular}

\section{Electrochemical studies}

Potentiodynamic polarization studies

To analyse the impact of nicotinamide on the polarization behaviour of aluminum, solutions of different nicotinamide concentrations $(1000,2000,3000$ 
and $4000 \mathrm{ppm}$ ) were set up in $0.5 \mathrm{M} \mathrm{HCl}$, and were then utilized for the polarization studies. The values of potential were plotted against the logarithm of current densities. Different computed parameters are given in Table 4.

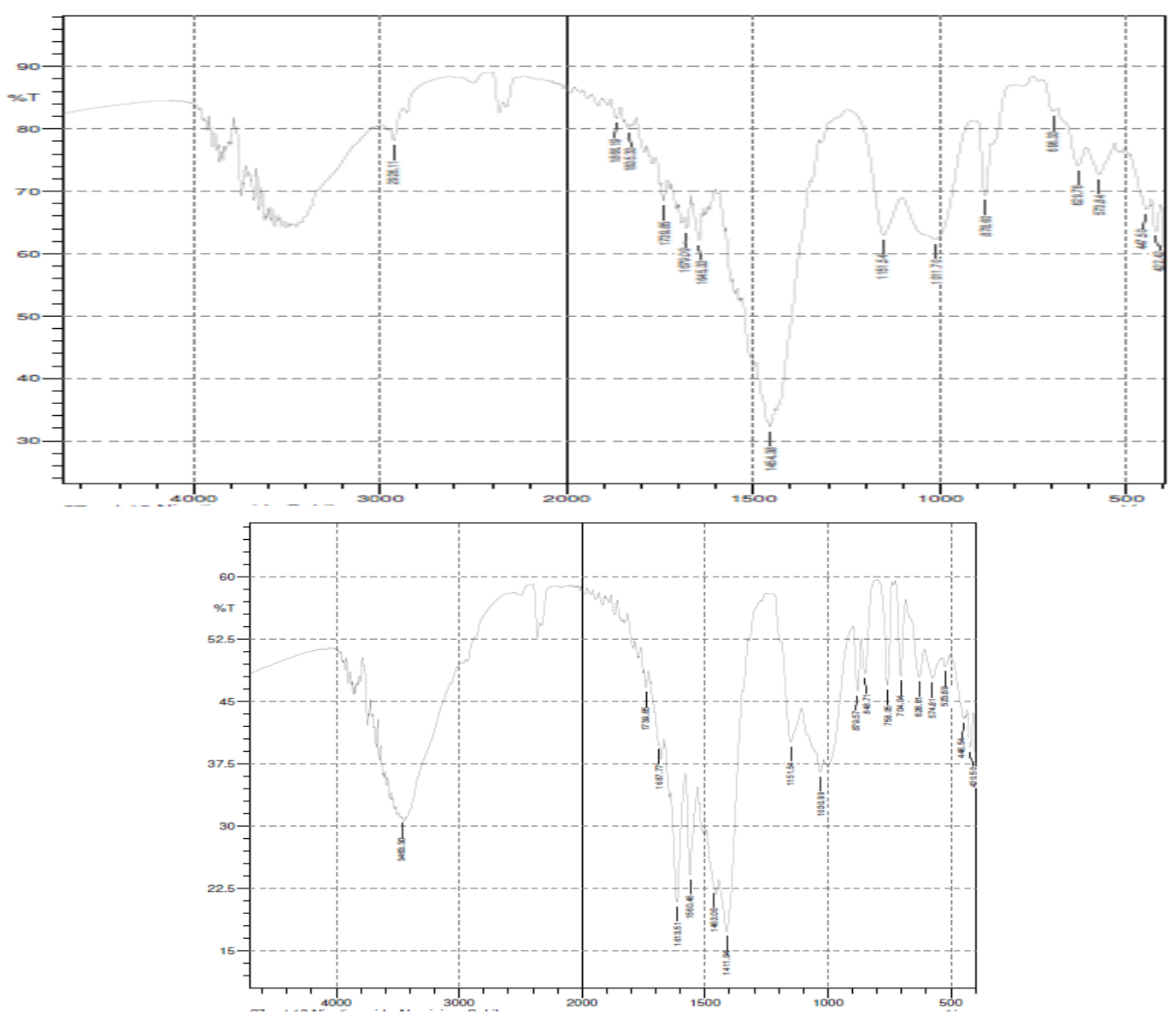

Figure 4. FTIR spectra of nicotinamide before and after aluminum immersion.

It is clear from Table 4 that both cathodic and anodic slopes are affected in the inhibitor presence. It can, therefore, be assumed that nicotinamide gets adsorbed when inhibiting $\mathrm{Al}$ corrosion in the $\mathrm{HCl}$ solution, by the precipitation of chloride salt on both cathodic and anodic sites of the metal oxide surfaces.

Fig. 5 gives the cathodic and anodic polarization bands for nicotinamide, at 298 $\mathrm{K}$. The corrosion inhibition efficiency was ascertained utilizing the following expression [38]:

$$
\eta \%=\left(\mathrm{I}_{\text {acid }}-\mathrm{I}_{\text {inhibitor }} / \mathrm{I}_{\text {acid }}\right) \times 100
$$

where $\mathrm{I}_{\text {acid }}$ is the corrosion current exhibited by aluminum in the acidic solution only, and Inhibitor is the corrosion current of the aluminum sample in the presence of inhibitor additives.

The estimations of $\mathrm{E}_{\text {corr }}$ (corrosion potential), $\mathrm{b}_{\mathrm{c}}$ and $\mathrm{b}_{\mathrm{a}}$ are the primary components which determine the inhibitor behavior. $\mathrm{E}_{\mathrm{corr}}$ values remain practically consistent, which shows that this is a mixed type inhibitor [39-40]. This, however, does not give any data about anodic and cathodic disintegration processes. These are exceptionally characterized by $b_{c}$ and $b_{a}$ values. If $b_{a}>b_{c}$, 
this indicates that the anodic disintegration process is more prevalent, and that the inhibitor will perform as an anodic type of inhibitor; and if bc >ba, then, the cathodic disintegration process is more prevalent, and the inhibitor will reveal to be of the cathodic type. In the present studies, $E_{\text {corr }}$ values remain almost constant, indicating the presence of a mixed type of inhibitor.

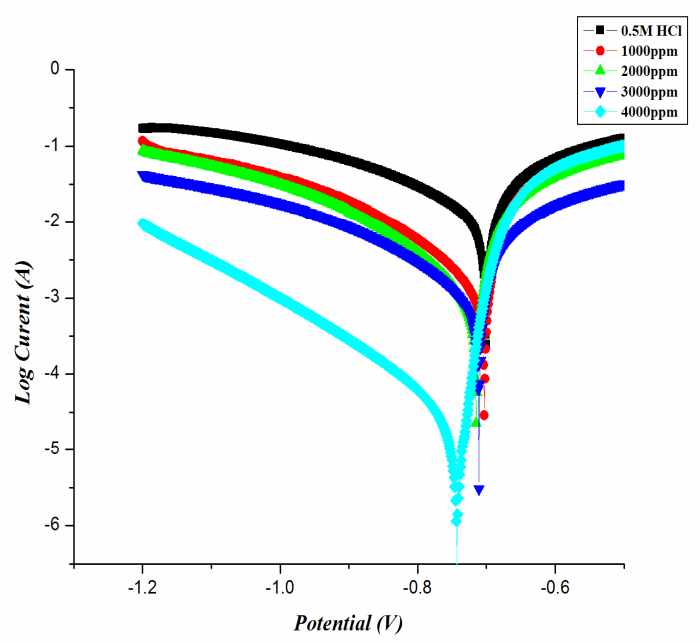

Figure 5. Tafel polarization curves for aluminum in $0.5 \mathrm{M} \mathrm{HCl}$, in the presence of various nicotinamide concentrations, at $298 \mathrm{~K}$.

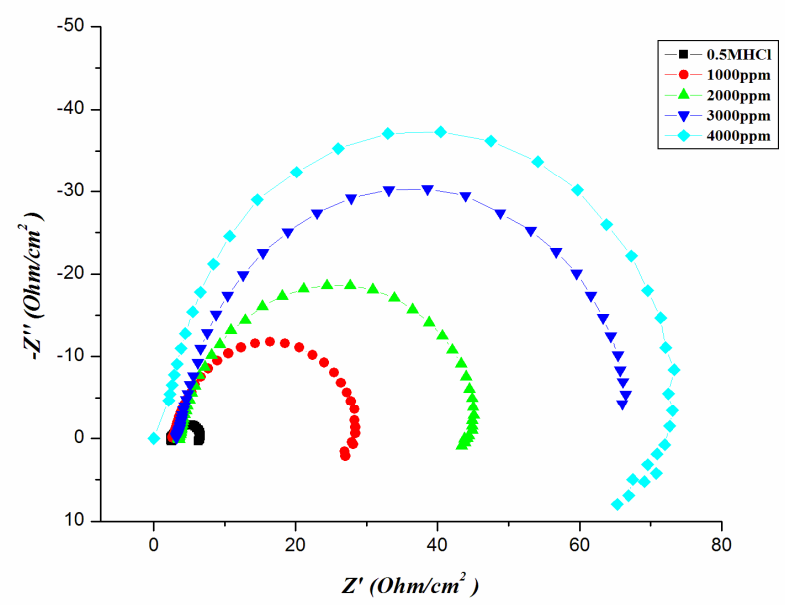

Figure 6. Nyquist plot for aluminum/0.5 M HCl, without and with various concentrations of nicotinamide.

Electrochemical impedance spectroscopy (EIS)

Aluminum corrosion in an acidic solution in nicotinamide presence was explored by EIS at $298 \mathrm{~K}$, after immersion for $30 \mathrm{~min}$. Double layer capacitance values $\left(\mathrm{C}_{\mathrm{dl}}\right)$ and charge transfer resistance values $\left(\mathrm{R}_{\mathrm{ct}}\right)$ were measured from impedance estimation. The estimation of charge transfer resistance was determined by measuring the width of the semicircle. The double layer capacitance was figured out utilizing the following equation:

$$
C_{d l}=1 /\left(2 \pi f_{\max } R_{c t}\right)
$$


where $f_{\max }$ is the frequency where the imaginary part of the impedance (i.e., Z") has maximum magnitude.

The corrosion inhibition efficiency was calculated by using the following equation:

$\eta E I S(\%)=($ Rct inhibitor - Rct acid/ Rct inhibitor $) \times 100$

where Rctinhibitor is the charge transfer resistance exhibited by aluminum in nicotinamide presence in an acidic solution, and Rct $_{\text {acid }}$ is the charge transfer resistance of the aluminum sample without and with nicotinamide.

Fig. 6 shows the Nyquist plot for aluminum/0.5 M HCl, without and with various concentrations of nicotinamide.

Fig. 7 and 8 show the Bode plots (Log Freq. (Hz) vs. (-) Phase (deg)) and (Log Freq. $(\mathrm{Hz})$ vs. $\left.\log \mathrm{Z}\left(\mathrm{Ohm} / \mathrm{cm}^{2}\right)\right)$, respectively, for aluminum in $0.5 \mathrm{M} \mathrm{HCl}$, without and with various nicotinamide concentrations.

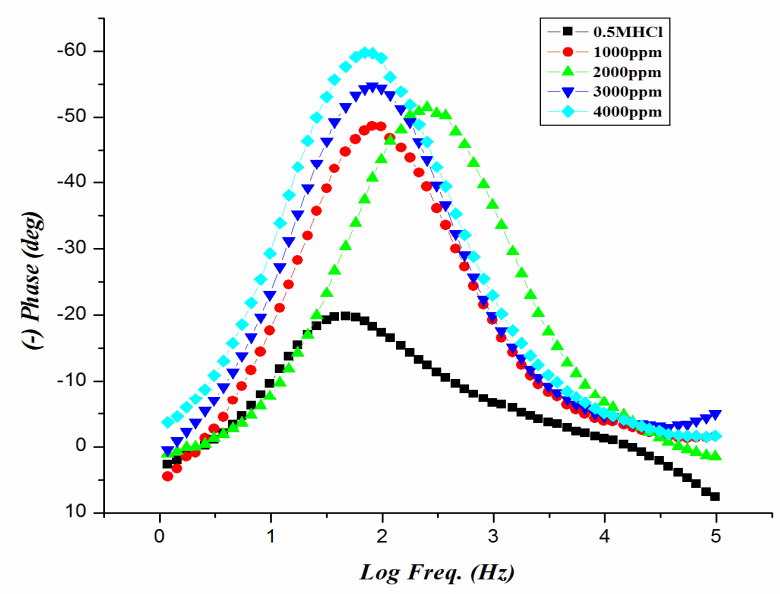

Figure 7. Bode plot (Log Freq. (Hz) vs. (-) Phase (deg)) for aluminum in $0.5 \mathrm{M} \mathrm{HCl}$, without and with various concentrations of nicotinamide.

Parameters obtained from EIS, and the calculated inhibition efficiency (IE \%) are given in Table 5 . $\mathrm{R}_{\mathrm{ct}}$ value increases in the inhibitor presence, which, in turn, leads to a decrease in the corrosion current for aluminum in $0.5 \mathrm{M} \mathrm{HCl}$. All nicotinamide concentrations perform best in $0.5 \mathrm{M} \mathrm{HCl}$, by enhancing $\mathrm{R}_{\mathrm{ct}}$ value and bringing down $\mathrm{C}_{\mathrm{dl}}$ value. $\mathrm{R}_{\mathrm{ct}}$ higher values in nicotinamide presence, as compared to the $\mathrm{R}_{\mathrm{ct}}$ value of acid, are indicative of greater inhibition efficiency [41].

\section{Quantum chemical results}

The optimized structures, graphical surfaces of the highest occupied molecular orbital (HOMO) and possible sites for electrophilic attack are displayed in Fig. 9. All quantum chemical parameters were obtained from the optimized structures of the lowest energy conformer.

The reactivity of nicotinamide was researched by investigating the frontier molecular orbitals. According to the frontier molecular orbital theory, the 
chemical reactivity is strongly determined by the interaction of the highest unoccupied molecular orbital (HOMO) with the lowest unoccupied molecular orbital (LUMO) of the interacting species [41].

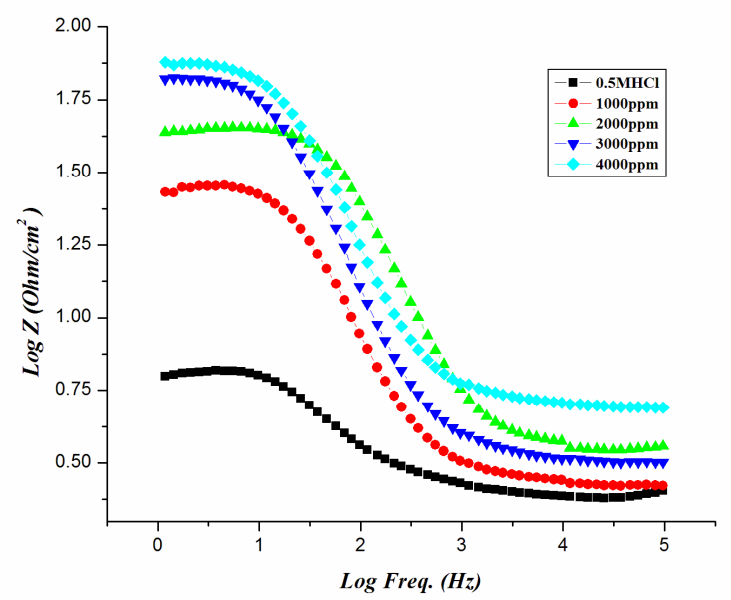

Figure 8. Bode plot (Log Freq. (Hz) vs. $\log \mathrm{Z}\left(\mathrm{Ohm} / \mathrm{cm}^{2}\right)$ ) for aluminum in $0.5 \mathrm{M} \mathrm{HCl}$, without and with various concentrations of nicotinamide.

Table 5. Impedance parameters for aluminum corrosion in $0.5 \mathrm{M} \mathrm{HCl}$ with nicotinamide.

\begin{tabular}{ccccc}
\hline $\begin{array}{c}\text { Conc. } \\
(\mathbf{p p m})\end{array}$ & $\begin{array}{c}\boldsymbol{R}_{\boldsymbol{c t}} \\
\left(\boldsymbol{\Omega} \mathbf{~ c m}^{-\mathbf{2}}\right)\end{array}$ & $\begin{array}{c}\boldsymbol{C}_{\boldsymbol{d l l}} \\
\left(\boldsymbol{\mu} \mathbf{~ F ~ \mathbf { ~ m } ^ { - 2 } )}\right.\end{array}$ & $\boldsymbol{\Theta}$ & $\begin{array}{c}\boldsymbol{\eta} \text { EIS } \\
(\boldsymbol{\%})\end{array}$ \\
\hline 1000 & 25.3 & 167.7 & 0.84 & 84.7 \\
2000 & 40.6 & 84.3 & 0.90 & 90.4 \\
3000 & 64.0 & 43.3 & 0.93 & 93.9 \\
4000 & 70.6 & 3.2 & 0.94 & 94.5 \\
& & & & - \\
$0.5 \mathrm{M} \mathrm{HCl}$ & 3.8 & 590.2 & --- & - \\
\hline
\end{tabular}

Other quantum chemical parameters were calculated so to have more insight into nicotinamide reactivity. The frontier molecular orbital energies (i.e., E HOMO and $_{\text {HOM }}$ $\left.\mathrm{E}_{\mathrm{LUMO}}\right)$ provide information on the reactivity of chemical species. $\mathrm{E}_{\mathrm{HOMO}}$ is often associated with the electron donating ability of a molecule [42-43], and a higher Еномо energy value indicates higher tendency of the molecule to donate electron(s) to the appropriate acceptor molecule with low energy and empty/partially filled molecular orbital. The results reported in Table 6 show the estimated values of quantum chemical parameters.

Molecules with large $\Delta \mathrm{E}\left(\mathrm{E}_{\mathrm{LUMO}}-\mathrm{E}_{\mathrm{HOMO}}\right)$ values are highly stable and associated with low reactivity, while molecules with small $\Delta \mathrm{E}$ values are generally highly reactive. A molecule with a small $\Delta \mathrm{E}$ value is easily polarized, and can, therefore, be easily adsorbed onto the metal surface, resulting in appreciably good inhibition efficiency. 


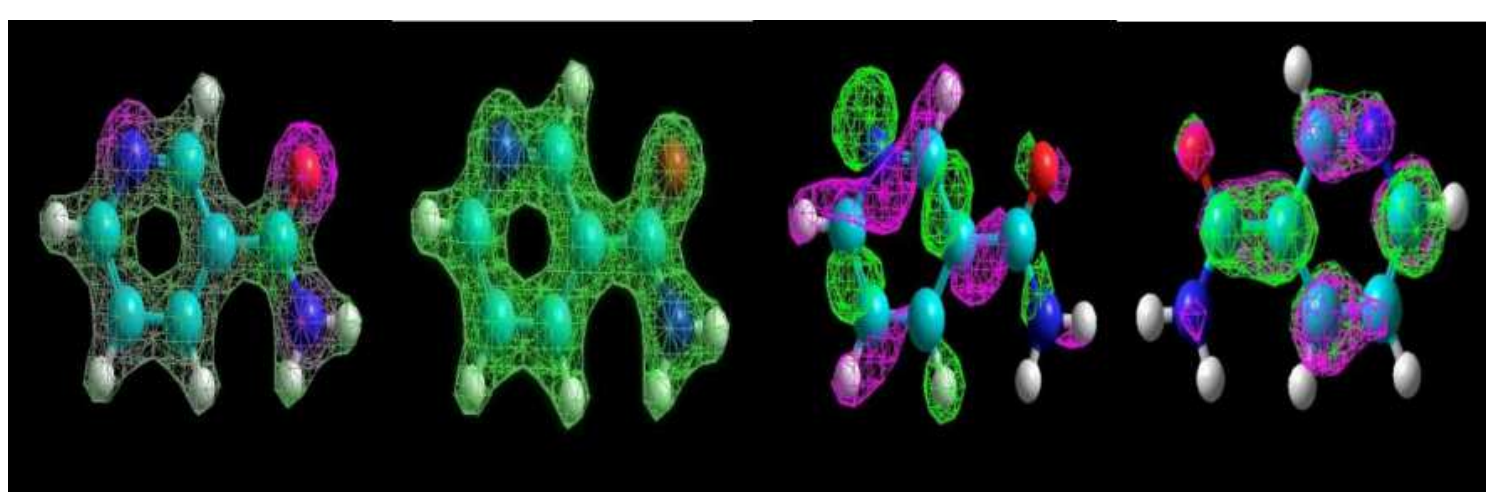

Figure 9. 3D mapped structure, total charge density, highest occupied molecular orbital (HOMO) and lowest unoccupied molecular orbital (LUMO) for the studied compound (nicotinamide).

Table 6. Calculated quantum chemical parameters for nicotinamide.

\begin{tabular}{cccc}
\hline $\begin{array}{c}\text { Eномо } \\
\text { (Hartree) }\end{array}$ & $\begin{array}{c}\text { Elumo } \\
(\text { Hartree) }\end{array}$ & $\begin{array}{c}\text { ELLumo-еномо } \\
\text { (Hartree) }\end{array}$ & $\begin{array}{c}\text { Dipole } \\
\text { moment, } \boldsymbol{\mu} \text { (Debye) }\end{array}$ \\
\hline-8.6 & 0.4 & -1.2 & 3.3 \\
\hline
\end{tabular}

The dipole moment $(\mu)$ is another index that is often used for the prediction of the relative ability of corrosion inhibitors. It is the measure of polarity in a bond, and it is related to the distribution of electrons in a molecule [45]. Inhibitors with high dipole moments tend to form strong dipole-dipole interactions with the metal, which result in strong adsorption onto the metal surface, thus leading to greater inhibition efficiency [46-47]. However, a survey of literature shows that, in most cases, experimental inhibition efficiencies do not always correlate with dipole moments [48-49]. The results reported in Table 6 show that nicotinamide has appreciable dipole moments, which facilitate its adsorption onto the aluminum surface.

\section{Monte Carlo simulation results}

Electronic properties alone are not adequate to foresee the pattern of the inhibition properties of the explored inhibitor, regardless of their ability to investigate the inhibition mechanism. We carried out Monte Carlo technique to test possible low energy searches of the inhibitors' configuration space on a clean aluminum surface in an aqueous solution, as the temperature steadily diminished. The most stable low energy adsorption configurations of nicotinamide on (Al 111) $/ \mathrm{H}_{2} \mathrm{O}$ framework utilizing Monte Carlo studies are portrayed in Fig. 10 and Fig 11.

The qualities for the yields and descriptors of the Monte Carlo calculations are recorded in Table 7 . It is very evident from this table that the adsorption energies of the inhibitors on the Al surface, in water presence, were expanded. It is by and large recognized that the essential phenomenon of aluminum corrosion inhibition occurs by adsorption. So, the adsorption energy can provide us with immediate information about the efficiency of inhibitors. In all cases, the adsorption energy of nicotinamide is far higher than that of water molecules (Table 7). This shows 
the likelihood of a steady substitution of water molecules from the aluminum surface, bringing about the formation of a protective layer which thereby inhibits corrosion on the aluminum surface.

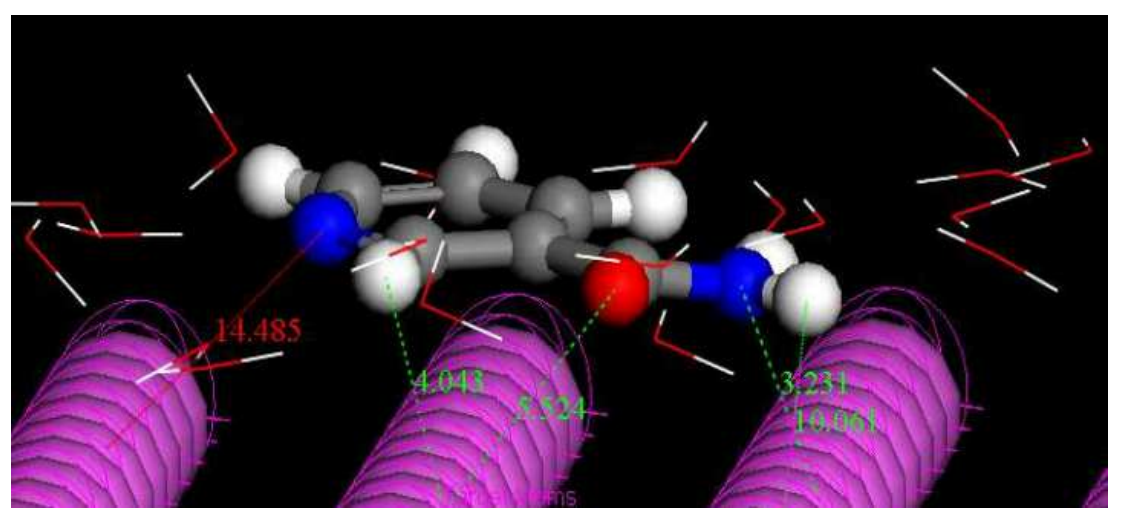

Figure 10. The most stable low energy configuration for nicotinamide adsorption on $\mathrm{Al}(111) / 50 \mathrm{H}_{2} \mathrm{O}$ system, obtained using the Monte Carlo simulation, side view.

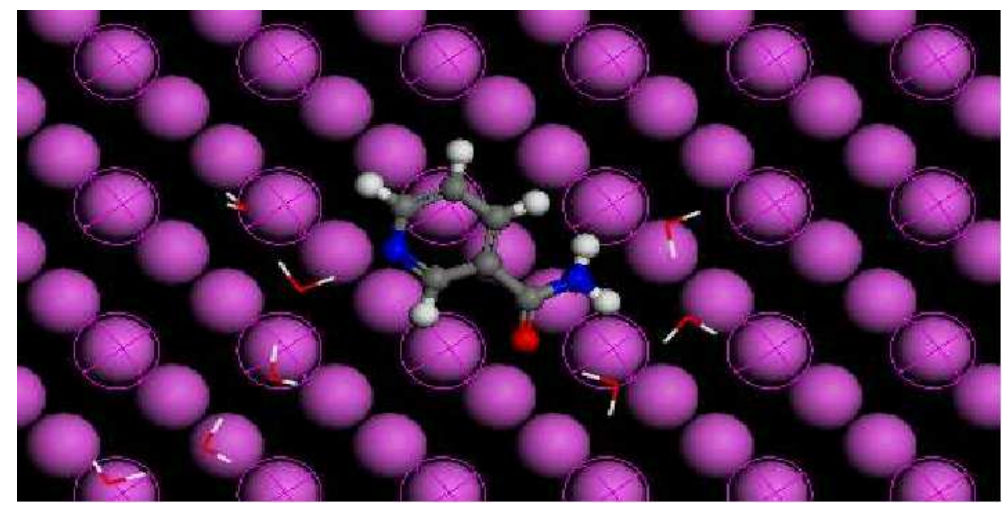

Figure 11. The most stable low energy configuration for nicotinamide adsorption on $\mathrm{Al}(111) / 50 \mathrm{H}_{2} \mathrm{O}$ system obtained using the Monte Carlo simulation, top view.

Table 7. Outputs and descriptors calculated by the Monte Carlo simulation for the lowest adsorption configurations of nicotinamide on $\mathrm{Al}(111) / 50 \mathrm{H}_{2} \mathrm{O}$ interface (in $\mathrm{kcal} / \mathrm{mol})$.

\begin{tabular}{ccccccc}
\cline { 4 - 6 } $\begin{array}{c}\mathrm{Al}(111) \\
\text { Nicotinamide/ }\end{array}$ & $\begin{array}{c}\text { Total } \\
\text { energy }\end{array}$ & $\begin{array}{c}\text { Adsorption } \\
\text { energy }\end{array}$ & $\begin{array}{c}\text { Rigid } \\
\text { adsorption } \\
\text { energy }\end{array}$ & $\begin{array}{c}\text { Deformation } \\
\text { energy }\end{array}$ & $\begin{array}{c}\text { Nicotinamide } \\
\text { dEad/dNi }\end{array}$ & $\begin{array}{c}\mathbf{H}_{2} \mathbf{O}: \\
\mathbf{d E a d} / \mathbf{d N i}\end{array}$ \\
\cline { 5 - 7 } & -472.5 & -451.5 & -471.5 & 20.0 & -38.6 & -3.3 \\
\hline
\end{tabular}

\section{Scanning electron microscopy}

The surface morphologies of plain aluminum surfaces and aluminum in $0.5 \mathrm{M}$ $\mathrm{HCl}$, without and with 4000 ppm of nicotinamide, are exhibited in Fig. 12.

It is clear that plain aluminum, before immersion in a $0.5 \mathrm{M} \mathrm{HCl}$ solution, displays a smooth surface. The aluminum coupon immersed in a $0.5 \mathrm{M} \mathrm{HCl}$ solution, without inhibitors, showed a profoundly rough and disintegrated surface due to corrosion; the aluminum coupon immersed in a solution of $4000 \mathrm{ppm}$ in $0.5 \mathrm{M} \mathrm{HCl}$ showed a visibly smooth surface with much less pores and cavities. 
This indicates that nicotinamide provides a defensive covering on the aluminum surface, thus inhibiting corrosion [50].

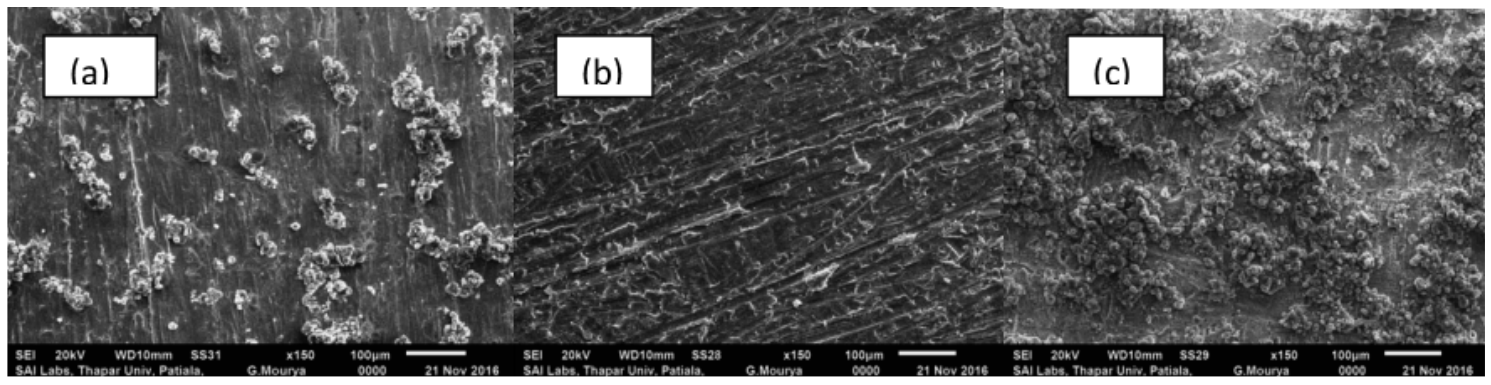

Figure 12. SEM images of aluminum surface: (a) plain aluminum, (b) aluminum immersed in $0.5 \mathrm{M} \mathrm{HCl}$ and (c) in the presence of a nicotinamide solution (4000 ppm) in $0.5 \mathrm{M} \mathrm{HCl}$.

\section{Conclusions}

Corrosion inhibition properties of nicotinamide were investigated on aluminum in $0.5 \mathrm{M} \mathrm{HCl}$, using electrochemical methods, spectroscopic techniques, quantum chemical calculations and Monte Carlo simulations. The following conclusions were drawn from the results:

1. Nicotinamide studied in this work showed appreciable inhibition efficiency of $99.9 \%$ for aluminum corrosion in $0.5 \mathrm{M} \mathrm{HCl}$, at $4000 \mathrm{ppm}$. The inhibition efficiency increased with increasing inhibitors concentration.

2. Potentiodynamic polarization study showed that nicotinamide is a mixed type inhibitor, and the EIS study revealed that this inhibitor formed a protective film on the aluminum surface. The experimental results showed that nicotinamide spontaneously adsorbs onto the aluminum surface, and conforms to the Langmuir adsorption isotherm.

3. SEM images also confirmed the formation of protective films by nicotinamide on the aluminum surface.

4. FTIR spectra revealed the occurrence of chemical interactions between nicotinamide and aluminum.

5. Quantum chemical parameters, such as $\mathrm{E}_{\text {HOMO }}$ and $\mathrm{E}_{\mathrm{LUMO}}$, and dipole moments agree with the experimental results.

6. Monte Carlo studies reveal that the adsorption energy of the nicotinamide is far higher than that of water molecules, thereby suggesting the formation of a protective layer.

\section{References}

1. Obi-Egbedi NO, Essien KE, Obot IB, et al. 2-Diaminoanthraquinone as corrosion inhibitor for mild steel in hydrochloric acid: weight loss and quantum chemical study. Int J Electrochem Sci. 2011;6:913.

2. Kumar A, Bashir S. Review on Corrosion inhibition of Steel in Acidic media. Int J Chem Tech Research. 2015;8:391. 
3. Umoren SA, Obot IB, Ebenso EE, et al. The inhibition of aluminium corrosion in hydrochloric acid solution by exudate gum from Raphia hookeri. Desalination. 2009;247:561.

4. Obot IB, Obi-Egbedi NO, Umoren SA. The synergistic inhibitive effect and some quantum chemical parameters of 2, 3-diaminonaphthalene and iodide ions on the hydrochloric acid corrosion of aluminium. Corros Sci. 2009;51:276.

5. Bhrara K, Singh G. Effect of allyl triphenyl phosphonium bromide on electrochemical and corrosion behaviour of mild steel in $0.5 \mathrm{M}$ sulphuric acid. Corros Eng Sci Technol. 2007;42:137.

6. Bethencourt M, Botana FJ, Calvino JJ, et al. Lanthanide compounds as environmentally-friendly corrosion inhibitors of aluminium alloys: a review. Corrosion Science. 1998;40:1803.

7. Obot IB, Obi-Egbedi NO, Umoren SA. Antifungal drugs as corrosion inhibitors for aluminium in 0.1 M HCl. Corros Sci. 2009;51:1868.

8. Kumar A, Bashir S. Ethambutol: A new and effective corrosion inhibitor of mild steel in acidic medium. Russ J Appl Chem. 2016;89:1158.

9. Akpan IA, Offiong NO. Effect of ethanolamine and ethylamine on the entropy content of the corrosion of mild steel in tetraoxosulphate (VI) acid solution. Chem Mater Res. 2012;2:40.

10. Fouda AS, Gadow HE. Streptoquin and Septazole: Antibiotic drugs as corrosion inhibitors for copper in aqueous solutions. Global J Res Eng. 2014 Sep 30.

11. Ramdé T, Rossi S, Bonou L. Corrosion inhibition action of Sulfamethoxazole for brass in acidic media. Int $\mathrm{J}$ Electrochem Sci. 2016;11:6819.

12. Shukla SK, Singh AK, Ahamad I, et al. Streptomycin: A commercially available drug as corrosion inhibitor for mild steel in hydrochloric acid solution. Mater Lett. 2009;63:819.

13. Ahamad I, Prasad R, Quraishi MA. Inhibition of mild steel corrosion in acid solution by Pheniramine drug: Experimental and theoretical study. Corros Sci. 2010;52:3033.

14. Al-Baghdadi SB, Noori FT, Ahmed WK, et al. Thiadiazole as a potential corrosion inhibitor for mild steel in $1 \mathrm{M} \mathrm{HCl}$. J Adv Electrochem. 2016:67.

15. Obot IB, Obi-Egbedi NO. Fluconazole as an inhibitor for aluminium corrosion in $0.1 \mathrm{M} \mathrm{HCl}$. Colloids Surf, A Physicochem Eng Asp. 2008;330:207.

16. Bhat JI, Alva VD. Inhibition Effect of Miconazole Nitrate on the Corrosion of Mild Steel in Hydrochloric Acid Medium. Int J Electrochem. 2011;2011.

17. Karthikeyan S, Jeeva PA, Raja K. Dicloxacillin: An effective retarder for steel dissolution in acid medium. Int J Chem Tech Research. 2015;8:1391.

18. Singh P, Chauhan DS, Srivastava K, et al. Expired atorvastatin drug as corrosion inhibitor for mild steel in hydrochloric acid solution. Int $\mathbf{J}$ Ind Chem. 2017;8:363. 
19. Thanapackiam P, Rameshkumar S, Subramanian SS, et al. Electrochemical evaluation of inhibition efficiency of ciprofloxacin on the corrosion of copper in acid media. Mater Chem Phys. 2016;174:129.

20. Reza I, Saleemi A, Naveed S. Corrosion inhibition of mild steel in $\mathrm{HCl}$ solution by Tinidazole. Polish J Chem Technol. 2011;13:67.

21. Abdallah M. Rhodanine azosulpha drugs as corrosion inhibitors for corrosion of 304 stainless steel in hydrochloric acid solution. Corros Sci. 2002;44:717.

22. Ahamad I, Quraishi MA. Mebendazole: new and efficient corrosion inhibitor for mild steel in acid medium. Corros Sci. 2010;52:651.

23. Vaszilcsin N, Ordodi V, Borza A. Corrosion inhibitors from expired drugs. Int J Pharm. 2012;431:241.

24. Hebbar N, Praveen BM, Prasanna BM, et al. Anthranilic acid as corrosion inhibitor for mild steel in hydrochloric acid media. Proc Mater Sci. 2014;5:712.

25. Kumar SH, Karthikeyan S. Amoxicillin as an efficient green corrosion inhibitor for mild steel in $1 \mathrm{M}$ sulphuric acid. J Mater Environ Sci. 2013;4:675.

26. Adejoro IA, Ojo FK, Obafemi SK. Corrosion inhibition potentials of ampicillin for mild steel in hydrochloric acid solution. J Taibah Univ Sci. 2015;9:196.

27. Kumar H, Karthikeyan S. Inhibition of mild steel corrosion in hydrochloric acid solution by cloxacillin drug. J Mater Environ Sci. 2012;3:925.

28. Naqvi I, Saleemi AR, Naveed S. Cefixime: A drug as efficient corrosion inhibitor for mild steel in acidic media. Electrochemical and thermodynamic studies. Int J Electrochem Sci. 2011;6:146.

29. Umoren SA, Obot IB. Polyvinylpyrollidone and polyacrylamide as corrosion inhibitors for mild steel in acidic medium. Surf Revi Lett. 2008;15:277.

30. Oguzie EE. Corrosion inhibition of aluminium in acidic and alkaline media by Sansevieria trifasciata extract. Corros Sci. 2007;49:1527.

31. Garai S, Garai S, Jaisankar P, et al. A comprehensive study on crude methanolic extract of Artemisia pallens (Asteraceae) and its active component as effective corrosion inhibitors of mild steel in acid solution. Corros Sci. 2012;60:193.

32. Lebrini M, Robert F, Lecante A, et al. Corrosion inhibition of C38 steel in 1 $\mathrm{M}$ hydrochloric acid medium by alkaloids extract from Oxandra asbeckii plant. Corros Sci. 2011;53:687.

33. Raja PB, Qureshi AK, Rahim AA, et al. Neolamarckia cadamba alkaloids as eco-friendly corrosion inhibitors for mild steel in $1 \mathrm{M} \mathrm{HCl}$ media. Corros Sci. 2013;69:292.

34. Oguzie EE. Evaluation of the inhibitive effect of some plant extracts on the acid corrosion of mild steel. Corros Sci. 2008;50:2993.

35. Bashir S, Singh G, Kumar A. Shatavari (Asparagus Racemosus) as green corrosion inhibitor of aluminium in acidic medium. J Mater Environ Sci. 2017;8:4284. 
36. Lebrini M, Robert F, Lecante A, et al. Corrosion inhibition of C38 steel in 1 $\mathrm{M}$ hydrochloric acid medium by alkaloids extract from Oxandra asbeckii plant. Corros Sci. 2011;53:687.

37. Kumpawat N, Chaturvedi A, Upadhyay RK. Comparative study of corrosion inhibition efficiency of naturally occurring ecofriendly varieties of holy basil (tulsi) for tin in $\mathrm{HNO}_{3}$ solution. Open J Metal. 2012;2:68.

38. Satar MZ, Noor MF, Samsudin MW, et al. Corrosion inhibition of aluminium by using nipah (Nypa fruticans) extract solution in hydrochloric acid $(\mathrm{HCl})$ media. Int J Electrochem Sci. 2012;7:1958.

39. Satapathy AK, Gunasekaran G, Sahoo SC, et al. Corrosion inhibition by Justicia gendarussa plant extract in hydrochloric acid solution. Corros Sci. 2009;51:2848.

40. Kamal C, Sethuraman MG. Spirulina platensis-A novel green inhibitor for acid corrosion of mild steel. Arab J Chem. 2012;5:155.

41. Arslan T, Kandemirli F, Ebenso EE, et al. Quantum chemical studies on the corrosion inhibition of some sulphonamides on mild steel in acidic medium. Corros Sci. 2009;51:35.

42. Singh A, Pramanik T, Kumar A, et al. Phenobarbital: A New and Effective Corrosion Inhibitor for Mild Steel in $1 \mathrm{M} \mathrm{HCl} \mathrm{Solution.} \mathrm{Asian} \mathrm{J} \mathrm{Chem.}$ 2013;25:9808.

43. Odiongenyi AO, Odoemelam SA, Eddy NO. Corrosion inhibition and adsorption properties of ethanol extract of Vernonia amygdalina for the corrosion of mild steel in $\mathrm{H}_{2} \mathrm{SO}_{4}$. Port Electrochim Acta. 2009;27:33.

44. Mert BD, Mert ME, Kardaş G. Experimental and theoretical investigation of 3-amino-1, 2, 4-triazole-5-thiol as a corrosion inhibitor for carbon steel in $\mathrm{HCl}$ medium. Corros Sci. 2011;53:4265.

45. Issa RM, Awad MK, Atlam FM. Quantum chemical studies on the inhibition of corrosion of copper surface by substituted uracils. Appl Surf Sci. 2008;255:2433.

46. Ibrahim MA, Messali M, Moussa Z, et al. Corrosion inhibition of carbon steel by imidazolium and pyridinium cations ionic liquids in acidic environment. Port Electrochim Acta. 2011;29:375.

47. Sasikumar Y, Adekunle AS, Olasunkanmi LO, et al. Experimental, quantum chemical and Monte Carlo simulation studies on the corrosion inhibition of some alkyl imidazolium ionic liquids containing tetrafluoroborate anion on mild steel in acidic medium. J Mol Liq. 2015;211:105.

48. Singh P, Ebenso EE, Olasunkanmi LO, et al. Electrochemical, theoretical, and surface morphological studies of corrosion inhibition effect of green naphthyridine derivatives on mild steel in hydrochloric acid. J Phys Chem C. 2016;120:3408.

49. Singh A, Ebenso EE. Use of Glutamine as a new and effective corrosion inhibitor for mild steel in $1 \mathrm{M} \mathrm{HCl}$ solution. Int $\mathrm{J}$ Electrochem Sci. 2013;8:12874.

50. Bashir S, Sharma V, Lgaz H, et al. The inhibition action of analgin on the corrosion of mild steel in acidic medium: A combined theoretical and experimental approach. J Mol Liq. 2018;263:454. 